present. Clinical and histological features in patients with or without atopy were compared, but no evidence was obtained that would shed light on this problem.

Requests for advice on the probability of conceiving affected males may be made by female members of families with sex-linked ichthyosis. As the carrier state cannot be detected on clinical and histological grounds, and the gene is not closely linked with the Xg blood-group locus, genetical predictions can be based only on conventional Mendelian analysis.

\section{Summary}

Three hundred and eighty-nine persons with ichthyosis ascertained in a population survey were examined. Through classifying patients by mode of inheritance the clinical and histological characteristics of common varieties of ichthyosis due to autosomal dominant or sex-linked genes were defined. Comparison of characteristics showed that separation of the two groups was possible. Apart from differences in distribution of ichthyosis on the body surfaces, males with sex-linked ichthyosis were more extensively affected and scaling did not improve with advancing years. By contrast, autosomal dominant ichthyosis was a milder condition with less prominent scales, and was frequently associated with manifestations of atopy, keratosis pilaris, and chapping. The appearance of the latter variety corresponds to the previous descriptive terms ichthyosis nacrée or nitida and of the former variety to ichthyosis saurodermia or serpentina.
The population frequency of ichthyosis was discussed and an unexpectedly high prevalence of sex-linked ichthyosis noted in Berkshire.

We wish to thank Dr. A. C. Stevenson for suggesting the investigation and for hetp and criticism while it was beng completed, Dr. A. H. T. Robb-Smith for providing histological facilities, Dr. R. R. Race and Dr. R. Sanger for Xg blood-grouping, and all the consultant dermatologists, general practitioners, and school medical officers of health in the Oxford Regional Hospital Board area for referring patients. In addition, Miss K. Major and Miss R. Mason provided indispensable help when visiting families and during all stages of the investigation.

\section{REFERENCES}

Alibert, J. L. (1806). Descriptions des maladies de la peau observées d̀ l'hôital Saint-Louis. Barrois l'ainé, Paris.

Chan, E. (1950). Chin. med. F., 68, 378.

Cockayne, E. A. (1933). Inherited Abnormalities of the Skin and its Appendages. Oxford University Press, London.

Greither, A. (1964). Dermatologica (Basel), 128, 464. Hebra, F., and Kaposi, M. (1874). On Diseases of the Skin, vol. 3, London.

Kerr, C. B., and Wells, R. S. (1965). Ann. hum. Genet., 29, 33.

L and Sanger, R. (1964). Lancet, 2, 1369.

Lomholt, G. (1963). Psoriasis, p. 204. Gad, Copenhagen

Radcliffe Crocker, H. (1896). Atlas of the Diseases of the Skin. Young, Edinburgh and London.

Rayer, P. (1835).A Theoretical and Practical Treatise on the Diseases of the Skin. Baillière, London.

Touraine, A. (1958). Ann. Derm. Syph. (Paris), 85, 257.

Wells, R. S., and Kerr, C. B. (1965). Arch. Derm., 92, 1

(1966). F. invest. Derm. In press.

Willan, R. (1808). On Cutaneous Diseases. Johnson, London. Wilson, Erasmus (1857). On Diseases of the Skin. Churchill, London.

\title{
Treatment of "Refractory Obesity" with a Diet of Five Meals a Day
}

\author{
J. F. MUNRO,* M.B., CH.B., M.R.C.P.ED. ; D. A. SEATON,* M.D., M.R.C.P.ED., M.R.C.P.GLASG. \\ L. J. P. DUNCAN,* M.B., B.SC., F.R.C.P.ED.
}

Brit. med. F., 1966, 1, 950-952

Though a wide variety of dietary regimens and many drugs said to have appetite-reducing properties have been recommended for the treatment of obesity, they have all too often been ineffective when subjected to critical study. However, attention has recently been drawn to the effects on weight of varying feeding habits, and Hollifield and Parson (1962) have shown that rats given infrequent access to food become heavier than those allowed unrestricted "nibbling." Similarly, the incidence of excess weight in elderly Czechoslovakian men has been reported to be greater in those taking no more than three meals each day than in those taking at least five meals (Fábry et al., 1964). Treatment of obesity by allowing frequent small meals has previously been assessed (Gordon et al., 1963), but the results, though encouraging, are not strictly valid, as the dietary modifications were associated with the use of triiodothyronine and diuretics. A clinical trial is reported in which hospital outpatients having " refractory obesity" (Duncan et al., 1960) were treated with a diet of five 200-calorie meals each day for 12 weeks.

\section{Selection of Patients and Conduct of Trial}

Thirty-nine adult women were chosen for the study. Most were housewives and all were obese, being at least $20 \%$ overweight (United States Medico-Actuarial Investigations, 1912), but none showed clinical evidence of cardiac failure or oedema.
Five patients were mild diabetics, who on diet alone had only occasional postprandial glycosuria. All had attended the dietetic out-patient department regularly for at least the previous 12 months, during which time their attempts to adhere to prescribed subcaloric diets containing approximately 1,000 calories had met with little or no success and resulted in no

TABle I.-Relevant Data for the 35 Patients (Mean Age 54.9 Years Range 40-75) Who Completed the Study

\begin{tabular}{|c|c|c|c|}
\hline & & lb. & kg. \\
\hline 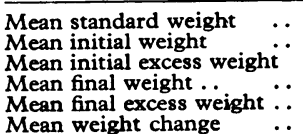 & $\begin{array}{l}\ldots \\
\because \\
\because \\
\because\end{array}$ & $\begin{array}{l}142 \cdot 0(127-171) \\
195 \cdot 1(156-303) \\
39 \cdot 7 \%(20-77 \%) \\
189 \cdot 7(145-296) \\
35 \cdot 5 \%(11-73 \%) \\
-5 \cdot 4(+2--22)\end{array}$ & $\begin{array}{c}64.4(57 \cdot 6-77 \cdot 6) \\
90 \cdot 3(70 \cdot 8-137 \cdot 4) \\
86 \cdot 0(65 \cdot 8-134 \cdot 3) \\
-2.45(+0.9--10 \cdot 0)\end{array}$ \\
\hline
\end{tabular}

significant loss of weight in the three months immediately preceding the trial. Fourteen patients had completed an earlier trial of two 500-calorie meals a day nine months previously (Seaton and Duncan, 1964), but thereafter regained weight and none had taken anorexigenic drugs for at least one year. The relevant data for the 35 patients who finished the trial are given in Table I.

* Diabetic and Dietetic Department and University Department of Therapeutics, the Royal Infirmary, Edinburgh. 
The patients were given a list of over 70 meals or snacks, each containing approximately 200 calories, and told that they could take five of these meals each day. They were allowed no other foods except drinks containing neither milk nor sugar.

The list of meals provided a wide variety of foods and were suitable for all times of the day. Some fairly representative examples are as follows: (1) $\frac{1}{2}$ grapefruit, $1 \mathrm{oz}$. (28 g.) bread. (2) Clear soup with vegetables, 2 oz. ( $57 \mathrm{~g}$.) meat with vegetables (except potatoes, peas, or beans), 5 oz. (142 g.) stewed apples (3) 1 oz. (28 g.) lean bacon, 1 egg fried in bacon fat. (4) $1 \mathrm{oz}$. ( $28 \mathrm{~g}$.) bread (toasted), $1 \frac{1}{2} \mathrm{oz}$. (42 g.) sardines. (5) $1 \mathrm{oz}$. (28 g.) peanuts. (6) $2 \mathrm{oz}$. (57 g.) gingerbread. (7) 1 pint $(142 \mathrm{ml}$.) milk, $\frac{1}{4}$ oz. (7 g.) Ovaltine or Horlicks, 1 rich tea or digestive biscuit. (8) Recipes for various dishes, including savoury custard, kebabs, cheese meringue. (9) Meals of soup and meat and apple snow ; soup and meat and vegetables; salmon mayonnaise and jelly; cold meat and salad and fruit; meat pie and milk pudding. (10) Snacks of biscuits, butter, and cheese ; chocolate biscuit ; ice-cream ; coffee and biscuits ; sandwiches.

Patients reported to a special clinic at fortnightly intervals for 12 weeks. At these visits each patient was weighed wearing, so far as was possible, the same indoor clothes, and any diffculties experienced with the diet were discussed. Adherence to the diet was classified as "strict " or " not strict" according to the information given by the patient.

\section{Results}

Two patients defaulted because they found the diet intolerable and two who went out to work were unable to adhere to the meals listed. The other 35 were satisfied with the variety in their diet, and only seven complained at any time of hunger; this was never severe, and it disappeared as the trial progressed.

The mean loss of weight during the 12-week period was 5.4 lb. $(2.46 \mathrm{~kg}$.). Table II summarizes the average two-weekly weight change and shows the number of patients who gained, lost, or remained unchanged in weight in each period. Six patients gained 1 to $2 \mathrm{lb}$. ( 0.45 to $0.9 \mathrm{~kg}$.) during the trial, three were unchanged in weight at the end of the trial, and the other 26 lost weight ; 18 lost from 1 to $9 \mathrm{lb}$. $(0.45$ to $4 \mathrm{~kg}$.), seven lost from 10 to $19 \mathrm{lb}$. (4.5 to $8.6 \mathrm{~kg}$.), and one patient lost $22 \mathrm{lb}$. (10 kg.). TaBle II.-Details of Weight Change at Two-weekly Intervals in 35
Patients on Five Meals per Day

\begin{tabular}{|c|c|c|c|c|c|c|c|c|}
\hline No. of Weeks or & Diet: & 2 & 4 & 6 & 8 & 10 & 12 & Total \\
\hline $\begin{array}{l}\text { Mean weight change } \\
\text { No. gaining weight } \ldots \\
\text { No. steady in weight .. } \\
\text { No. losing weight } \ldots\end{array}$ & $\left\{\begin{array}{c}\text { lb. } \\
\text { kg. } \\
\cdots \\
\cdots\end{array}\right.$ & $\mid$\begin{tabular}{c|}
$-2 \cdot 4$ \\
-1.09 \\
2 \\
4 \\
29
\end{tabular} & $\begin{array}{c}-0.9 \\
-0.41 \\
5 \\
9 \\
21\end{array}$ & \begin{tabular}{|c|}
-0.8 \\
-0.36 \\
8 \\
8 \\
19
\end{tabular} & $\begin{array}{c}-0.5 \\
-0.23 \\
10 \\
8 \\
17\end{array}$ & $\begin{array}{c}+0 \cdot 3 \\
+0 \cdot 14 \\
17 \\
6 \\
12\end{array}$ & $\begin{array}{l}-1 \cdot 1 \\
-0 \cdot 5 \\
8 \\
2 \\
25\end{array}$ & $\begin{array}{c}-5 \cdot 4 \\
-2 \cdot 45 \\
6 \\
3 \\
26\end{array}$ \\
\hline
\end{tabular}

Mean weight loss was greatest in the first two-weekly period; thereafter it diminished progressively until the fifth period, when there was a small mean rise in weight. The weight loss in the final two-weekly period, however, was exceeded only by that in the first period, presumably because

TABLE III.-Comparison of Mean Weight Changes in Patients Classified as "Strict" and "Not Strict" in Their Adherence to the Diet

\begin{tabular}{c|c|c|c|c} 
& \multicolumn{4}{|c}{ Wo. of } \\
$\begin{array}{c}\text { Weeks on } \\
\text { Diet }\end{array}$ & "Strict " Patients (14) & "Not Strict" Patients (21) \\
\hline & lb. & g. & lb. & g. \\
\hline 2 & -3.0 & $-1,360$ & -2.0 & -907 \\
4 & -1.6 & -726 & -0.5 & -227 \\
6 & -1.3 & -590 & -0.5 & -227 \\
8 & -1.0 & -454 & -0.1 & +45 \\
10 & -0.6 & -272 & +0.9 & +181 \\
12 & -2.2 & -998 & -0.4 & $-1,179$ \\
\hline Mean Total & -9.7 & $-4,400$ & -2.6 & -108 \\
\hline
\end{tabular}

patients made an extra effort when they knew that the trial was approaching its end.

Table III compares the weight change of the 21 patients who admitted deviation from the prescribed regimen with the 14 patients who stated that they had adhered strictly to the diet throughout the trial. All of the latter lost weight, with a mean loss of $9.7 \mathrm{lb}$. (4:4 kg.), whereas nine of the not-strict group failed to lose weight, and mean weight loss was only $2.6 \mathrm{lb}$. (1.18 kg.).

\section{Discussion}

The patients in this study had all failed to lose weight on conventional subcaloric diets and thus provided a practical test of the value of any special therapeutic regimen.

The five meals a day diet is designed to avoid long fasts and to give food often enough and in sufficient quantity to prevent or relieve hunger and yet restrict calorie intake. Despite these theoretical advantages four patients failed to complete the trial, two finding the regimen impracticable and two intolerable. A further 21 patients were unable to adhere strictly to the diet. Thus for the majority of patients the diet proved unsatisfactory and loss of weight remained unimpressive. Indeed, there is little to be gained by persevering with the regimen once a patient admits to not being strict with the diet.

The remaining 14 patients adhered strictly to the diet throughout the 12 -week period, with a satisfactory mean weight loss of $9.7 \mathrm{lb}$. (4.4 kg.). This is greater than that achieved by various appetite-suppressing drugs in similar patients over a similar period (Duncan et al., 1960 ; Seaton et al., 1961, 1964a, 1964b). It is, however, slightly less than that achieved by patients adhering strictly to two 500-calorie meals a day (Seaton and Duncan, 1964) and definitely less than that obtained by using a formula diet (Seaton and Duncan, 1963).

Unfortunately at present there is no way of predicting which patients will manage to follow the diet strictly, though this may be possible by studying the patients' previous eating habits to determine whether they are natural " gorgers " or " nibblers." In this trial, however, all the patients had been taking conventional subcaloric diets for at least the preceding six months, and consequently it was impossible to determine whether the best effects were achieved by controlling or breaking bad dietary habits, as these had already been modified. Certainly it is diffcult to prophesy the most suitable diet for the individual obese patients, and some patients respond better to the five meals a day regimen and others to the two 500-calorie meals a day diet. For example, 14 of our patients had taken the two meals a day diet before the five meals a day diet and a further 14 were given the two diets in the opposite order. Of these 28 patients 16 did better on the two meals a day regimen, in two the results were comparable, and 10 did better on the five meals a day diet.

It is essential when managing patients with refractory obesity to maintain their interest and morale by frequent, if only minor, alterations in their treatment. Otherwise they will default. Thus, however desirable, it is almost impossible to perform a trial with a lengthy follow-up period in such patients, especially if the majority are not losing appreciable weight, as was the case in this study. None the less, this 12-week trial has shown the five meals a day scheme to be an acceptable form of diet to the majority of patients and a valuable dietary regimen for those who can adhere to it strictly.

\section{Summary}

The results are reported of a trial of 1,000-calorie diet given as five 200 -calorie meals each day for 12 weeks to 39 patients having "refractory obesity."

Four patients defaulted from the study. The mean loss of weight was $5.4 \mathrm{lb}$. $(2.45 \mathrm{~kg})$, being $9.7 \mathrm{lb}$. $(4.4 \mathrm{~kg}$.) in those 
adhering strictly to the diet and $2.6 \mathrm{lb} .(1.18 \mathrm{~kg}$.) in those deviating from it.

The five meals a day diet was acceptable to many patients with " refractory obesity," but the results were satisfactory only in those who adhered strictly to the diet.

We wish to thank Miss E. M. Wilson for preparing the diets and for assistance with the study.
REFERENCES

Duncan, L. J. P., Rose, K., and Meiklejohn, A. P. (1960). Lancet, 1, 1262.

Fábry, P., Fodor, J., Heil, Z., Braun, T., and Zvolánková, K. (1964). Ibid., 2, 614 .

Gordon, E. S., Goldberg, M., and Chosy, G. J. (1963). F. Amer. med. Ass., 186, 50.

Hollifield, G., and Parson, W. (1962). f. clin. Invest., 41, 245.

Seaton, D. A., and Duncan, L. J. P. (1963). Brit. med. f., 2, 219. - (1964). Lancet, 2, 612.

- Rose, K., and Scott, A. M. (1961). Brit. med. F., 1, 1009. Rose, K., and Duncan, L. J. P. (1964a). Practitioner, 193, 698

- - (1964b). Scot. med. f., 9, 482 .

\title{
Recurrent Infection of the Urinary Tract: Reinfection or Recrudescence?
}

\author{
JAMES MCGEACHIE,* M.D., M.C.PATH.
}

Brit. med. F., 1966, 1, 952-954

Though infections of the urinary tract may respond to modern antibacterial therapy, the frequency of recurrent urinary infections has altered little from the pre-antibiotic era (Rhoads, Billings, and O'Conor, 1952). The frequency of recurrence depends to a great extent on the pathogenesis of the infection; obviously where some obstructive factor is present the probability of recurrence is high without the necessary correction of the underlying defect. Even where no associated lesion of the urinary tract is apparent the rate of recurrence is still frequent (Garrod, Shooter, and Curwen, 1954 ; Jackson, Poirier, and Grieble, 1957). Indeed it is probably true to say that, though the bacteriological cure of urinary infection has been accelerated with the use of modern therapy, the recurrence rate following short-term therapy is no lower than formerly. The problem with recurrence may be expressed by the question, Is recurrence a recrudescence of an inadequately eradicated infection or is it an infection by a new organism? Where the recurrence is associated with a different species, assuming that this species was absent from the initial infection, then little doubt can exist that this is a reinfection. However, where the species isolated is the same in both episodes then the differentiation requires further classification other than biochemical. It was hoped that by employing serological and colicine typing methods some clarification of the problem might be obtained.

\section{Material and Methods}

Forty-nine patients attending the medical renal clinic or in-patient medical wards of the Glasgow Royal Infirmary were investigated for 108 recurrent infections with Escherichia coli over four years. Each patient had an established infection with $E$. coli which responded to treatment and was followed by a further infection with $E$. coli. Infection was accepted by the presence of more than 100,000 organisms per ml. of urine, demonstrated by the quantitative bacterial-count technique described previously (McGeachie and Kennedy, 1963). Where possible two or more pretreatment, mid-stream specimens of urine were obtained to confirm the presence of significant bacteriuria. Of the 49 patients with recurrent infections 37 females and the sole male had no demonstrable abnormality of the urinary tract. The remaining 11 , all females, had the following abnormalities: glomerulonephritis (3), acute tubular necrosis (3), nephrosis (1), renal calculus (1), KimmelstielWilson kidneys (1), duplication of the renal pelvis (1), and

* Lecturer, University Department of Bacteriology, Glasgow Royal Infirmary. disseminated sclerosis (1). These 11 patients had 39 recurrent episodes.

The patients were prescribed a course of appropriate antibacterial therapy, which varied from 5 to 10 days. The proof of eradication of infection was taken by the continued sterility of urine, associated with the absence of symptoms and pyuria, during treatment, for at least two days after the cessation of therapy, and again at 10 days or longer. Indication of recurrence was considered when there was a bacterial count of more than 100,000 organisms per $\mathrm{ml}$. of urine following the period of sterile urine cultures. Further mid-stream specimens were obtained at the medical renal clinic at two weeks, at one month, then at monthly intervals for six months to one year, then at three-monthly intervals for a further year, and, should no further episodes of infection occur, at six-monthly intervals for the next two years.

It is not intended to discuss the therapeutic management of urinary infection in detail, however; it will be sufficient to state that the short-term therapy was used only for the comparison of antibacterial substances, and as a rule long-term treatment was the method of choice.

Methods of Investigation.-The colonies of $E$. coli were isolated on the diagnostic culture plates and subcultured on to nutrient agar slopes, incubated for 18 hours at $37^{\circ} \mathrm{C}$., allowed to cool to room temperature, and stored at $4^{\circ} \mathrm{C}$. If it was not possible to investigate the subcultures within a few days they were lyophilized. The cultures were typed by . serological methods and by colicine production and colicine-sensitivity methods.

Serological Grouping.-The preparation and methods for serological grouping have been described in detail elsewhere (McGeachie, 1965a). The antisera used were prepared against 12 specific O groups-O1, O2, O4, O5, O6, O7, O8, O9, O11, $\mathrm{O} 18$, O39, and $\mathrm{O} 75-$ in which the majority of pathogenic strains have been found to occur (Vahine, 1945 ; Kauffman, 1947 ; Ujváry, 1958 ; Rantz, 1962 ; McGeachie, 1965a).

Colicine Typing.-Colicines are specific antibiotic substances produced by the Enterobacteriaceae ; they are bactericidal to other strains which have the appropriate receptor point on their surface. The property of producing colicine is a highly stable hereditary characteristic of bacteria which is governed by colicinogenic factors (Fredericq, 1965). Thus the typing of a strain of $E$. coli may be performed by using its colicine production pattern and its colicine sensitivity pattern as markers. The methods of colicine typing employed in this study have been described in detail elsewhere (McGeachie, 1965b). A freezethaw method of colicine extraction from the culture was used 